\title{
DO LETRAMENTO ESCOLAR AO LETRAMENTO PROFISSIONAL: UMA RELAÇÃO A CONSTRUIR
}

\section{FROM SCHOOL LITERACY TO PROFESSIONAL LITERACY: A RELATION TO BUILD}

\author{
Elisabeth Bautier \\ Université Paris 8, Saint Denis, France \\ Maíra de Araujo Mamede \\ Université Paris Est Créteil (UPEC), Créteil , France
}

Resumo: $O$ artigo propõe as bases de uma relação entre desigualdades no acesso aos usos escolares das potencialidades da escrita pelos alunos e a maior ou menor familiaridade dos professores com esses usos nas suas práticas profissionais. Em um primeiro momento, apresentamos nosso trabalho sobre as modalidades pedagógicas implementadas pelos professores, os suportes de ensino utilizados e os obstáculos encontrados pelos alunos em função de sua familiaridade com as práticas de linguagem próprias do letramento amplo. Isso nos leva a pensar em desigualdades educacionais em função dos usos da escrita construídos nas salas de aula. Para terminar, definimos o que seria um "letramento profissional" dos professores: um conjunto de conhecimentos e competências, condição para a implementação da democratização do acesso ao letramento amplo para todos os alunos.

Palavras-chave: Letramento; Desigualdade Escolar; Práticas Docentes; Práticas de Linguagem; Democratização Escolar

Abstract: The article proposes the bases for thinking together inequalities in the access to
scholar uses of writing potentialities among students with a greater or lesser familiarity of
teachers with theses ues in their professional practices. As a first step, we present our work on
teaching methods implemented by teachers, teaching resources and obstacles encountered by
students depending on their familiarity with literate language practices. This leads us to think
of educational inequalities in relation to these uses built in the classrooms. Finally, we define
what would be a "professional literacy" for teachers themselves, a set of knowledge and
competences, seen as a condition for the implementation the democratization of access to
extended literacy for all students. Keywords: Literacy; School Inequalties; Teacher Practices; Language Practices; School Democratization 
Nos últimos dez anos, após a difusão na Europa das pesquisas anglo-saxônicas sobre os New literacy studies (FRAENKEL; MBODJ, 2010), acumularam-se os estudos que analisam o uso do conceito de letramento e procuram estabilizar o seu sentido. Eles contribuíram para sua definição no contexto escolar, paradoxalmente, uma definição que enfatiza a natureza plural dos usos da escrita e de seus recursos. Não há um letramento, mas diversos letramentos, em função dos contextos e dos objetos (BARRÉ DE MINIAC et al., 2004; RISPAIL, 2011). Portanto essa definição de letramento não o limita à aquisição da leitura e da escrita. Ela inclui o papel das potencialidades da escrita na aprendizagem escolar, as maneiras de raciocinar que são construídas e, mais amplamente, os usos da linguagem escrita e oral relacionados a essas potencialidades. Devemos certamente ver no desenvolvimento da referência a essa definição do letramento em contexto escolar uma necessidade heurística: ele torna possível explicar o que está em jogo cognitivamente, linguisticamente e socialmente para os sujeitos em sua relação com a cultura escrita e as práticas de escrita, e ao fazê-lo, melhor entender as barreiras de aprendizagem encontradas no ambiente escolar por alguns alunos.

Não se trata portanto mais de ver no trabalho escolar "unicamente" os vestígios do (não) domínio da escrita no sentido de uma aquisição dos padrões da linguagem escrita e da textualidade, por mais diferentes que sejam os textos em função dos diferentes gêneros que atualizam. Trata-se de pensar a escrita como um conjunto de práticas sociais e sistemas cognitivos que se atualizam em uma determinada sociedade e aos quais a escola deve familiarizar os alunos, práticas que simultaneamente mobilizam dimensões linguísticas, mas também de linguagem e, portanto enunciativas, cognitivas. Práticas que apresentam, ainda, dimensões subjetivas e sociais.

A escolarização dos alunos na França se insere em uma "sociedade do documento" na qual "o mundo é colocado no papel"1 tal como definida por Olson e Lejosne (2006), uma sociedade na qual a escrita é onipresente, como referência para a construção do conhecimento, como critério de legitimidade do raciocínio e do conhecimento, e como critério de prova. É também uma sociedade das mídias, ainda que elas sejam digitais ou audiovisuais, o que implica familiaridade com a escrita para ser compreendido e "lido". Trata-se, portanto, de considerar a escrita não apenas em termos de técnicas ou como um fim em si mesmo (uma produção escolar a ser avaliada), mas como um recurso para pensar, raciocinar, estabelecer relações entre diversos dados, como um recurso também para falar, argumentar, elaborar saberes e conhecimentos tanto dentro da sala de aula, quanto na sociedade em geral.

Essa mudança não apenas na concepção dos escritos escolares, mas também das metas e objetivos da escola e das situações de aula levanta uma dupla questão. Por um lado, a primeira se refere à possibilidade de letramento amplo, e não restrito (ver abaixo), para todos os alunos, justamente porque nem todas as crianças frequentam fora da escola tais usos e práticas da linguagem socialmente construídos e socialmente situados. A segunda questão é a da implementação de uma concepção específica dos usos da linguagem e da escrita nas salas de aula, para que os alunos possam frequentar e aprender esses usos de linguagem e de pensamento fundados na cultura escrita. Em outros termos, é a relação dos professores com esse letramento escolar no próprio contexto da profissão que também está em questão. Tratase de questionar e analisar aqui aquilo que nomeamos práticas de letramento profissional $^{2}$ na perspectiva de democratização do letramento amplo dos alunos. Se os próprios professores não estão familiarizados com os usos de um letramento profissional, eles não podem incorporar esta exigência de letramento escolar em seu trabalho.

\footnotetext{
${ }^{1}$ Tradução das autoras.

2 Através do uso deste termo, buscamos identificar as implicações do letramento no exercício da profissão docente, com o objetivo de integrá-lo mais facilmente a uma formação profissional distinta do domínio das disciplinas acadêmicas.
} 
Essas duas questões são o conteúdo deste artigo, organizado em duas partes. A primeira apresenta os problemas colocados pela necessidade da aprendizagem do letramento escolar e sua desigual apropriação pelos alunos nas situações de trabalho propostas, a partir de pesquisas realizadas anteriormente em nosso grupo de pesquisa, de uma rede interuniversitária e de uma pesquisa que acaba de ser concluída. A segunda parte desenvolve uma reflexão sobre as condições de um ensino mais igualitário por meio de práticas profissionais, elas próprias construídas no "letramento profissional".

Ressalta-se que os trabalhos evocados no texto se referem ao contexto francês de escolaridade. As observações de aula que levam aos resultados descritos foram realizadas em instituições localizadas na rede de educação prioritária ${ }^{3}$. O mesmo vale para as recomendações institucionais às quais podemos nos referir. Essa focalização no contexto escolar deixa de fora outros contextos em que as crianças circulam e que também participam do desenvolvimento de outras práticas de letramento.

Um esclarecimento sobre os contextos científicos que mobilizam o conceito de letramento é necessário. Na França, usamos o termo "pratiques littératiées" para caracterizar os usos e práticas de linguagem (escritos e falados) que, por suas características, alinham-se à cultura escrita. A tradução deste termo para o português é difícil porque a adjetivação do termo letramento nos levaria a usar "letrado/letrada", um termo que se presta a confusão com o significado mais comum do termo, no sentido de cultivado. Neste artigo, interessamo-nos pela familiaridade com a cultura escrita e suas potencialidades, os modos de pensar construídos em familiaridade com a escrita. Mantivemos a expressão "littératiés/littératiéss" em francês nos casos em que a tradução se revelou infiel ao sentido almejado.

\section{DO LETRAMENTO ESCOLAR À PLURALIDADE DAS PRÁTICAS DE LETRAMENTO DOS ALUNOS: LETRAMENTO RESTRITO OU LETRAMENTO AMPLO, ORAL DE ELABORAÇÃO OU ORAL DE EXPRESSÃO?}

A distinção introduzida por Goody (2007) entre letramento restrito e letramento amplo bem como os trabalhos de Olson (1994) e Street (1993) mais precisamente, tornam possível não associar automaticamente a ação de escrever, e muito menos o grafismo, ao desenvolvimento cognitivo que permitiria a aprendizagem na escola ou ainda a compreensão do mundo. A referência a esses trabalhos torna ainda indissociável o letramento de seus usos sociais, sendo estes usos diversos tanto nas sociedades, consideradas na sua globalidade, mas também nas várias instâncias de socialização, nesse caso especificamente a família e a escola. Assim, são os usos da escrita (e não a escrita em si) que potencialmente produzem mudanças, tanto sociais quanto individuais e, consequentemente subjetivas e cognitivas.

Y. Reuter (2006) distingue, por sua vez, o letramento definido pelos usos "tradicionais" e funcionais da palavra escrita, como armazenamento ou memorização, daquilo que a escrita permite por causa de seus componentes estruturais, como a descontextualização, e a possibilidade de colocar em relação simultaneamente elementos presentes ou não na situação, a elaboração de novos conhecimentos ou raciocínios. Em suma, ele distingue a escrita em si daquilo que mais amplamente, utilizando os termos de Olson (1994), refere-se à exploração dos recursos culturais ligados à escrita e à sua frequentação.

Nessa abordagem ampla, diferentemente de uma abordagem tecnicista (e portanto reducionista) da aprendizagem da escrita, inclui-se os recursos da escrita, um raciocínio

\footnotetext{
3 As instituiçoes de ensino consideradas em "educação prioritária" na França são definidas pela composição social do público de alunos, menos favorecido. Elas são objetos de políticas específicas, tais como classes com um menor número de alunos, e incentivos salariais para os professores.
} 
baseado em saberes, e a mobilização da uma atividade cognitiva complexa. Essa distinção permite explicar a variedade de maneiras de utilizar a escrita em contexto escolar, nem todas com as mesmas potencialidades cognitivas e culturais. Por exemplo, uma atividade de cópia que pode favorecer a memorização não equivale a construir os princípios de uma categorização de elementos ou fenômenos por meio de uma formatação tabular articulando duas categorias.

Nos trabalhos de nosso grupo de pesquisa ${ }^{4}$, estudamos as situações escolares e as práticas específicas que implementam diferentes usos e mobilizam diferentes componentes deste objeto cultural que é a escrita. Pudemos assim colocar em evidência os processos de diferenciação passiva e ativa, bem como mostramos o desnivelamento de exigências de aprendizagem em um mesmo contexto, em uma mesma situação de ensino (ROCHEX; CRINON, 2011). Ressaltamos que nossos trabalhos, em coerência com as definições acima, não estão centrados na aprendizagem de escrita e leitura, mas nas desigualdades de aprendizagens disciplinares para as quais, nas situações atuais de ensino, os diferentes usos da escrita e suas potencialidades cognitivas são fundamentais. Neste sentido, os recursos cognitivos e culturais da escrita não se limitam somente às práticas de escrita, mas estão igualmente presentes nas trocas orais em sala de aula, o que nos levou a distinguir o oral de uma nova elaboração para os alunos de um oral espontâneo, ou de simples comunicação ou expressão (BAUTIER, 2016).

\subsection{ALGUMAS CONSTATAÇÕES ORIUNDAS DE NOSSAS ANÁLISES: DIVERSIDADE DAS PRÁTICAS DOS ALUNOS E DAS PRÁTICAS DE SALA DE AULA.}

Em primeiro lugar, em muitas aulas, especialmente em instituições com uma população escolar de origem popular, os momentos em que os alunos são convidados a escrever ou ler nas salas de aula podem ser caracterizados principalmente como práticas de letramento restrito, frequentemente, através de práticas de cópia, restituição de conhecimentos ou simplesmente em respostas curtas a perguntas orais ou escritas mobilizando um conhecimento já existente. Note-se que essas práticas de escrita não estão alheias às condições de realização que pesam sobre as práticas docentes, especialmente àquelas relacionadas ao controle do comportamento dos alunos, e para as quais esses momentos de escrita podem ser particularmente úteis para conter os corpos e obter silêncio.

Nossos trabalhos sobre os livros didáticos ou a literatura infantil (BONNÉRY, 2015; DELARUE-BRETON; BAUTIER, 2015a, 2015b) destacaram que eles eram objetos de diferenças significativas na compreensão e interpretação pelos alunos. De fato, esses suportes de trabalho tornaram-se atualmente muito complexos e pressupõem uma grande familiaridade com práticas "littératiées": heterogeneidade enunciativa e textual, pluralidade semiótica da informação (textos, imagens, fotos, diagramas coexistem), descontinuidade de textos, necessidade de estabelecer conexões para construir os significados de documentos e narrativas, não correspondência nos livros entre imagens e textos, significado de histórias que não se limita à sucessão de páginas, inúmeros implícitos. Tal diversidade e complexidade permitem interpretações, práticas de leitura e compreensão muito diferentes de acordo com as socializações familiares dos alunos. Enquanto alguns alunos aderem a compreensões factuais sucessivas de cada um dos elementos, interpretam documentos e narrativas no nível literal, na maioria das vezes relacionando-os com suas experiências e emoções familiares, outros identificam nesses suportes os enjeux cognitivos e conceituais, bem como os significados baseados nas intenções de textos e de seus autores além daquilo que está explicitamente

4 Équipe Circeft Escol, Université Paris 8 
formulado e da sucessão de eventos.

Consequentemente, nas "mesmas" situações, face aos "mesmos" suportes, nem todos os alunos obtêm os mesmos benefícios de aprendizagem, a mesma familiarização com o letramento. O primeiro grupo de alunos esvazia a complexidade dos suportes sem mesmo identificá-la. Além disso, e é isso que chamamos anteriormente de desnivelamento ou diferenciação passiva, uma adaptação das práticas de ensino ao contexto social do exercício docente, leva muitas vezes os professores a não exigir os mesmos tipos de compreensão e construção de significações, ou seja, de trabalho cognitivo em função do público escolar com quem trabalham, aceitando desempenhos mais simples e moderados precisamente para alunos que têm apenas a escola para aprender as exigências do letramento amplo, o que aumenta as desigualdades escolares.

É importante notar que o PISA (Programme for International Student Assessment) coloca justamente em evidência essas interpretações e competências de letramento diferenciadas dos itens que compõem a prova, que apresentam as mesmas características heterogêneas dos suportes descritos acima, mais ou menos exigentes do ponto de vista das práticas de letramento requeridas: identificar palavras em um texto e completar sentenças; relacionar elementos para responder a perguntas; dar uma opinião sobre um texto apoiando-se em saberes ou experiências transformadas em conhecimento. É assim que essas avaliações colocam em evidência as diferenças de competência dos jovens de 15 anos de idade. Aqueles que socialmente têm menos familiaridade com as práticas de letramento amplo conseguem apenas realizar os itens mais simples (BAUTIER, 2005, BAUTIER; RAYOU, 2013).

As práticas pedagógicas e didáticas atuais também introduzem situações que pressupõem hábitos de linguagem em conivência com as exigências escolares, mas introduzem assim desigualdades de aprendizagem. De fato, o ensino frontal é cada vez mais substituído pelo trabalho coletivo, por momentos de elaboração de saberes e de compreensões através de interações orais, que tomam a forma de aula dialogal (ou trabalho de grupo), da qual participam os alunos a partir de registros de trabalho diferentes em função do sentido que atribuem a essas trocas: trocas comunicativas ou expressão subjetiva de seus sentimentos e opiniões, ou, ao contrário, como um momento de elaboração coletiva de um novo conhecimento. Além da satisfação que pode ser obtida com a participação dos alunos nessas trocas, é necessário analisar de perto o tipo de registro de trabalho de linguagem a que se referem, para que situações orais também sejam uma ocasião de introduzir aos alunos às práticas de letramento amplo (BAUTIER, 2016).

\subsection{OS CADERNOS DOS ALUNOS: VESTÍGIOS DA FREQUENTAÇÃO DE DIFERENTES LETRAMENTOS ESCOLARES}

Uma pesquisa em fase de finalização permitiu abordar as práticas de sala de aula no tocante à escrita, os tipos de vestígios registrados nos cadernos dos alunos e, assim, mostrar as variações contextuais dessas práticas de acordo com a composição do público escolar. A partir dos vestígios escritos do que acontece nas situações de ensino-aprendizagem deixados nos cadernos escolares, procuramos caracterizar o processo de adaptação curricular do uso do letramento escolar em função dos contextos sociais dos estabelecimentos ${ }^{5}$. Coletamos cadernos de francês de alunos do sexto ano, início do colégio ${ }^{6}$, em cerca de quarenta

\footnotetext{
${ }^{5}$ Pesquisa ACCI Recherche ACCI - ACCI (adaptations curriculaires contextualisées et inégalités - adaptações curriculares contextualizadas e desigualdade), pesquisa sob a responsabilidade de M. Van Brederode realizada no âmbito do grupo de pesquisa Circeft EScol, Universidade Paris 8 e da Rede inter-universitária RESEIDA.

${ }^{6} \mathrm{O}$ sexto ano na França, primeiro ano do ensino secundário francês, corresponde ao sexto ano brasileiro, primeiro ano das séries finais do ensino fundamental, tendo em vista que o recorte entre os níveis de ensino primário e secundário não é o mesmo. Trata-se porém de alunos com a mesma faixa etária.
} 
instituições com recrutamento socialmente muito favorecidos ou entre muito desfavorecidos. Analisamos, então, as diferentes unidades de trabalho de uma mesma sequência de ensino, os contos. Esta entrada através das unidades de trabalho, caracterizadas em função das operações cognitivas solicitadas e, portanto, das variações do currículo real (FORQUIN, 2008), tornou possível uma comparação entre os contextos, socialmente contrastados.

Este material foi inicialmente analisado qualitativamente a partir das premissas extraídas de nossas pesquisas anteriores sobre as diferenças de frequentação pelos alunos de atividades "littératiées", uma abordagem que busca objetivar os indícios da natureza do trabalho proposto aos alunos, através da caracterização do tipo de atividade, das operações cognitivas solicitadas, dos materiais mobilizados e dos escritos produzidos pelos alunos. Em uma segunda etapa, esse material foi submetido a um tratamento quantitativo em análises qualitativas iniciais ${ }^{7}$. Para tanto, utilizamos análises de correspondência fatorial (AFC, ver exemplo infra), permitindo destacar a articulação das diferenças no uso do letramento escolar com os contextos sociais das escolas.

Constatamos, assim, que não existem diferenças significativas quanto à presença de diferentes momentos de trabalho (atividades de pesquisa, exercício, revisões/conclusões), ou seja os alunos são confrontados com formas de dar aula que são substancialmente semelhantes. Existem, no entanto, fortes diferenças, e elas dizem respeito justamente à frequentação do letramento amplo. Assim, o trabalho sobre léxico é mais importante nos contextos desfavorecidos, enquanto são os momentos de estudo do texto que estão sobrerepresentados em contextos favorecidos. Outras diferenças significativas para o nosso propósito dizem respeito à natureza do trabalho solicitado, materializado por diferentes atividades de escrita: em contexto favorecido, o professor solicita mais frequentemente os alunos para a realização de atividades de categorização, interpretação e produção, ao passo que em contexto desfavorecido, os alunos são mais solicitados a realizar exercícios de aplicação com vários itens da mesma natureza. Os primeiros alunos, portanto, usam a palavra escrita para elaborar o pensamento, são impelidos a refletir e estruturar o raciocínio, quando os segundos escrevem para fazer exercícios de aplicação e se exercitar através da repetição de um único e mesmo procedimento. Essa diferença torna-se ainda mais interessante quando se constata que não há diferença no número de palavras escritas nos cadernos. Logo, a diferença entre as atividades de escrita não é quantitativa, mas qualitativa: os alunos não são solicitados a fazer a mesma coisa quando escrevem em seus cadernos. Além disso, observamos diferentes tendências em relação aos suportes mobilizados. Enquanto, em contexto favorecido, os estudantes são confrontados com textos $\operatorname{longos}^{8}$ e complexos - descontínuos, integrando esquemas e outros elementos semióticos - em contexto desfavorecido, os alunos são confrontados com textos curtos, algumas raras vezes com quadros de categorização.

O diagrama abaixo mostra como se articulam as diferentes variáveis usadas para a análise quantitativa. $\mathrm{O}$ quadrante inferior esquerdo indica pela proximidade dos pontos que representam as variáveis que os cadernos resultantes de contextos escolares desfavorecidos (defavo) apresentam mais frequentemente as atividades que estão no domínio lexical (domlexiq), mais exercícios de aplicação (aplicação) com caráter repetitivo (exo5items). Os quadrantes do lado direito indicam, pela proximidade dos pontos que representam, as variáveis que os cadernos coletados em contextos favorecidos (favo) apresentam mais atividades relacionadas ao estudo do texto (demetudtxt), do qual eles devem extrair o conhecimento (contextintratxt), bem como atividades de escrita (redigertxtssources), classificação/categorização (classificationcateg) e interpretação/elaboração (interpretationelabo). De um ponto de vista formal, vê-se também que esses cadernos têm

\footnotetext{
${ }^{7}$ Vaquero (2019) utiliza o termo etnografia estatística para caracterizar essa abordagem que consiste em mobilizar um tratamento quantitativo de indícios qualitativos.

${ }^{8}$ Estabelecemos o limite entre textos considerados curtos e longos a dez linhas.
} 
mais signos gráficos de hierarquização (signsgraphiera) e mais esquemas (nbschema).

Figura 1: Diagramme de composantes

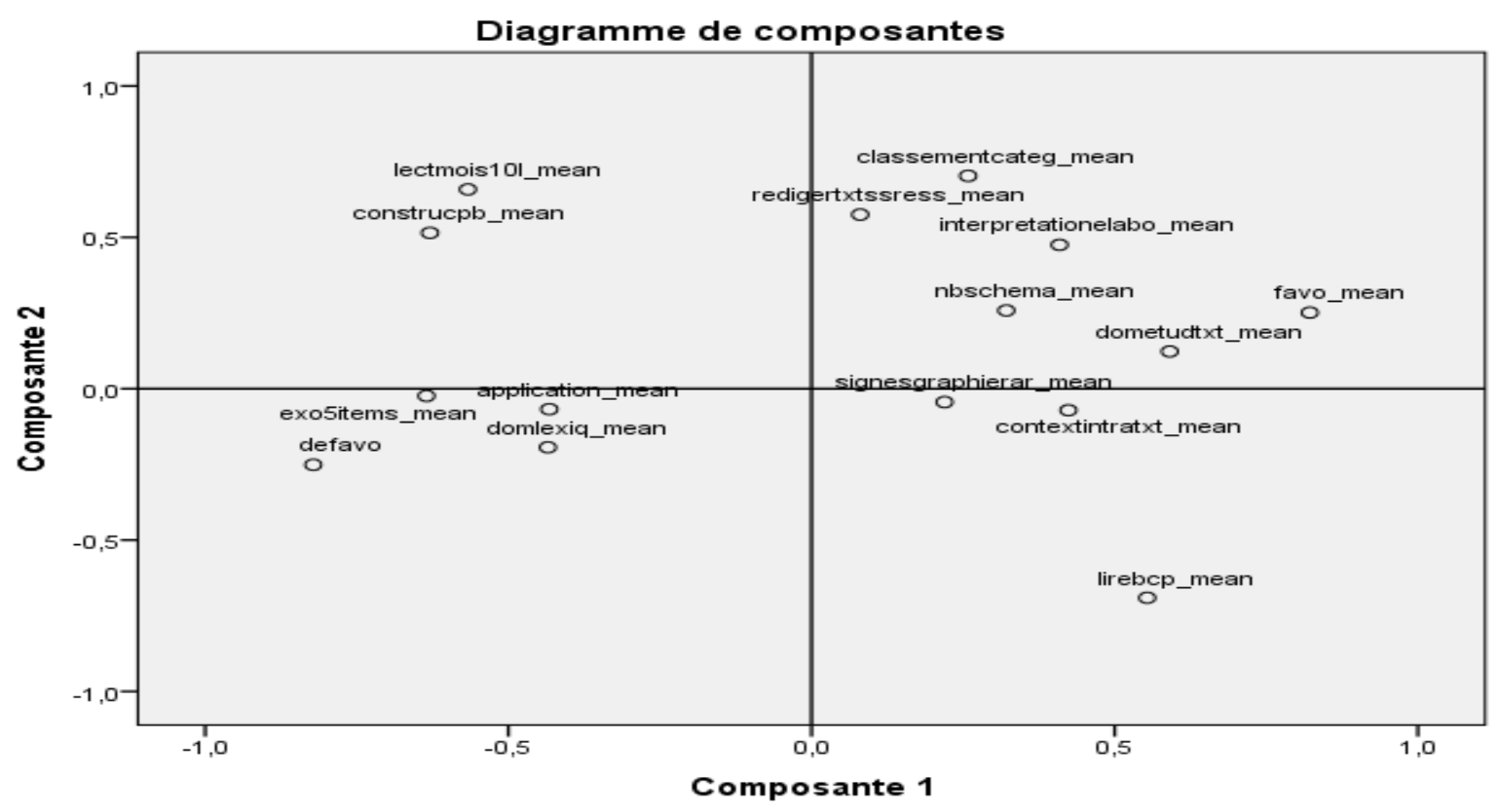

Fonte: os autores

Duas conclusões podem ser tiradas dessa pesquisa. Em primeiro lugar, tais diferenças contribuem para configurações de letramentos dissimilares, elas orientam os alunos para diferentes usos da escrita e do papel cognitivo da linguagem, que correspondem a um letramento restrito (GOODY, 2007), limitado em suas exigências e potencialidades ou, ao contrário, amplo, extenso, mas exigente. As salas de aula aparecem assim como contextos diferenciados e potencialmente diferenciadores de inserção no letramento (MAMEDE, 2011), na medida em que implementam diferentemente os recursos culturais relacionados à cultura escrita. Assim, os alunos não são confrontados às mesmas exigências de letramento. As diferenças na realização do currículo, que é supostamente o mesmo em todos as escolas, produzem contextos de escolarização que são diferenciados. Além disso, tais contextos tornam-se fortemente desiguais, uma vez que nem todos os alunos são igualmente socializados nas famílias às práticas cognitivas e às práticas de linguagem, suscetíveis de preparar para e completar a socialização escolar nessas mesmas práticas. Mas, em segundo lugar, além dos fenômenos de adaptação dos professores ao seu público, somos levados a olhar os conhecimentos e as práticas de letramento dos professores, em contexto profissional.

\section{O TRABALHO DOCENTE EXIGE O LETRAMENTO AMPLO}

Sendo a escola uma instituição intimamente ligada à cultura escrita, as mudanças sociais em termos de usos e práticas da palavra escrita têm implicações diretas na definição de objetivos e práticas escolares. $\mathrm{Na}$ escola francesa contemporânea, isso se traduz, de acordo com nossos trabalhos (ROCHEX; CRINON, 2011), em práticas de ensino caracterizadas pelo fato de colocar os alunos em atividade, bem como por trocas dentro da classe com o objetivo de lhes permitir raciocinar e elaborar saberes e conhecimentos. Os alunos devem ainda implementar atividades de análise, descontextualização e objetivação do conhecimento para ir além das situações de trabalho propostas e construir o conhecimento esperado. Tal aprendizado não é espontâneo para a maioria dos alunos, suas dificuldades são evidenciadas pelos maus resultados em avaliações internacionais. A edição 2015 do PISA (OCDE, 2016) 
confirmou a forte relação, no contexto francês, entre performance e origem social dos alunos, resultado que deixa supor que as práticas de ensino são pouco eficazes nesta área e, em particular, junto a alunos de meios desfavorecidos. Para esses alunos, a escola continua sendo uma experiência de letramento restrito, como se as práticas de ensino não tornassem o letramento amplo acessível a todos.

Isso nos leva a propor, nessa segunda parte, uma mudança de perspectiva: tirar o foco da aprendizagem dos alunos e propor um olhar sobre as implicações dessa transformação curricular para os professores. Nesta parte, formulamos hipóteses sobre o que seria um trabalho docente inscrito em hábitos "littératiés" e susceptível de permitir os alunos irem mais longe no caminho de um letramento amplo que permita os aprendizados. Essas hipóteses constituem objetos de pesquisa futuros.

Para permitir que todos os alunos tenham acesso ao letramento escolar esperado, é sem dúvida preciso que os professores saibam como construir situações capazes de permitir o investimento e a mobilização necessários pelos alunos, mas que saibam também acompanhálos na realização das atividades de linguagem esperadas. Isso requer mais clareza sobre os objetivos curriculares, bem como uma análise mais fina daquilo que as diferentes categorias de alunos mobilizam em suas atividades cognitivas e de linguagem (letramento restrito ou amplo, oral de comunicação ou oral de elaboração).

Como vimos anteriormente, se é possível analisar o tipo de letramento construído em sala de aula, também é possível, e mesmo necessário, analisar o tipo de letramento implementado no âmbito do trabalho do professor. No entanto, é difícil pensar no trabalho do professor em sala de aula, sem levar em conta o que acontece também fora da sala de aula, ou seja, as práticas profissionais que precedem o trabalho com os alunos, para conceber situações e documentos de trabalho, antecipar as dificuldades dos alunos, assim como aquelas que as sucedem, para analisar o trabalho dos alunos e ajustar as práticas. A escrita, esta é justamente uma de suas potencialidades, facilita a antecipação das situações de aula para pensar o ensino e as aprendizagens a longo prazo. Considerado desta forma, o letramento profissional docente consistiria em um trabalho de escrita do oficio docente e de leitura da aula, em uma articulação contínua entre o trabalho em sala de aula e o trabalho fora da sala de aula, antes e depois da interação com os alunos.

\subsection{ESCREVER O OFÍCIO PARA ANTECIPAR E INSCREVER OS SABERES E O LETRAMENTO NO LONGO PRAZO}

O trabalho de ensino pode ser pensado como um trabalho de tradução dos objetivos do currículo em situações de sala de aula. Este trabalho de tradução seria um trabalho de escrita, que permitiria a articulação das situações entre elas, mas também a articulação das diferentes situações ao programa. Escrever o ofício docente consiste assim em um trabalho de elaboração que possibilita inscrever tanto as interações entre alunos, quanto as atividades relacionadas a documentos ou suportes didáticos, em um programa de ensino-aprendizagem de maneira sistemática.

Este trabalho de "escrita", que permite colocar em relação os diferentes momentos de trabalho do professor, não pode ser reduzido ao fato de colocar por escrito o planejamento na forma de fichas. O ponto importante é menos o objeto em si, que a prática que ele possibilita. As fichas de planificação podem ser realizadas tanto em um processo de desenvolvimento e de reflexão, como elas podem ser feitas em um processo de consignação por escrito do trabalho extraclasse dos professores, para controle institucional. Escrever aparece neste segundo caso como uma ferramenta administrativa, ou respondendo aos requisitos institucionais, ao invés de ser um instrumento reflexivo e profissional. Considera-se sintomático da baixa importância dada ao trabalho fora da sala de aula que esta esfera do 
trabalho é muitas vezes negligenciada na formação e que os professores iniciantes sejam, consequentemente, mal acompanhados no desenvolvimento dessa prática de letramento profissional. $\mathrm{Na}$ ausência de conhecimentos disciplinares, didáticos e pedagógicos sólidos, mas principalmente na ausência de saberes sobre a centralidade do letramento amplo na aprendizagem escolar, os professores iniciantes nem sempre são capazes de escrever o trabalho nesse duplo nível curricular, ou seja, a aprendizagem de saberes técnicos da escrita e a entrada na cultura escrita.

Poucos estudos realmente analisam esse trabalho de escrita da profissão, poucas pesquisas se interessam pelos recursos mobilizados pelos professores para fazê-lo, a maneira como os chamados conhecimentos teóricos são colocados em relação com a realidade dos alunos de sua turma, conhecimentos que são, entretanto, necessários para o exercício profissional, para os procedimentos implementados, para os critérios de escolha das atividades/suportes/saberes... São no entanto, dimensões essenciais da expertise profissional de concepção e de antecipação, na relação que elas tecem com as práticas reais, sempre únicas porque contextualizadas e, portanto, nunca redutíveis ao que foi inicialmente concebido, planejado.

\subsection{LER A AULA PARA AJUDAR MELHOR OS ALUNOS A APRENDER}

Escrever o trabalho implicaria igualmente saber ler a aula, ou seja, saber identificar indícios pertinentes, tendo em vista os saberes existentes em linguística, em sociologia e psicologia da linguagem e da aprendizagem, para analisar o que está em jogo com os alunos em aula na frequentação dos usos do letramento escolar. Outros indícios estariam ligados às exigências de letramento amplo. Tratar-se-ia ainda de identificar os obstáculos cognitivos à aprendizagem dos conteúdos de saber e competências. Ajudar os alunos a aprender suporia, nesta perspectiva, sem dúvida que a atividade não seja avaliada somente no registro do que foi (bem/mal) feito e do produto terminado.

Ler a aula significaria assim mobilizar o letramento profissional para analisar as interações que acontecem em sala de aula, identificar o gênero de linguagem utilizado (mais elaborado ou, ao contrário, mais espontâneo e cotidiano) e o papel que cada um assume. Isso permitiria ao professor estar mais próximo do trabalho de cada aluno para analisar a linguagem e a atividade cognitiva e identificar os índices de sua pertinência.

\section{CONCLUSÃO - LETRAMENTO PROFISSIONAL E DEMOCRATIZAÇÃO DO ENSINO DO LETRAMENTO ESCOLAR: UM DESAFIO PARA A FORMAÇÃO E A PESQUISA}

A relação entre os usos diferenciados das práticas de escrita, como objetivo de aprendizagem, e os usos profissionais da escrita e de suas potencialidades, como condição de ensino sistemático de tais objetivos, permite pensar uma formação docente mais adaptada às exigências da escolarização contemporânea.

Lembramos que definimos esses usos neste artigo como aqueles relacionados à antecipação e preparação das sessões, bem como à análise das dificuldades dos alunos sobre a escrita e suas potencialidades, com base na mobilização de conhecimentos científicos, que devem ser pensados em relação à formalização da experiência que a reflexividade permite. Essa dimensão da profissão atual é aqui entendida como o conjunto de práticas de ensino tanto fora da sala de aula (escrever o ofício), quanto dentro (ler a aula) que mobiliza os recursos da escrita. Ela diz respeito também a um conjunto de conhecimentos sobre a entrada na cultura escrita e sua mobilização em sala de aula, seus componentes e práticas, que 
permitem aos professores tomar a medida de sua centralidade na aprendizagem escolar. Podem, assim, inserir essa dimensão em suas práticas como objeto de instrução e, consequentemente, de aprendizagem, inclusive e sobretudo para os alunos menos familiarizados com as práticas de letramento amplo, em suas diferentes esferas de socialização, dentre as quais a família.

De fato, nossas pesquisas nas salas de aula revelam a atenção desigual dada pelos professores a competências que são atualmente essenciais, como se sua realização pelos alunos pudesse resultar diretamente das práticas de sala de aula. No entanto, o letramento escolar amplo exige, ao contrário, que os professores o levem em conta como um objetivo curricular em si, da mesma maneira que os conteúdos disciplinares. Da mesma forma, a compreensão do que impede a aprendizagem nos alunos, particularmente os menos familiarizados com o letramento amplo, só pode ser alcançada levando-se em conta sua relação com a linguagem em geral e com a cultura escrita em particular. O desenvolvimento profissional dos professores, permitindo-lhes ser eficazes no ensino, requer o uso de potencialidades da escrita na própria atividade profissional.

O letramento profissional corresponde a competências complexas que os professores normalmente não exploram muito em formação, pois essa última está mais centrada nas didáticas disciplinares e na gestão da sala de aula. Isso participa da reprodução das desigualdades sociais na escola, especialmente quando se considera que as aprendizagens disciplinares são pensadas sem levar em conta sua inscrição nas condições de possibilidade da mobilização do letramento escolar amplo.

\section{Referências}

BAUTIER, É. Et si l'oral pouvait permettre de réduire les inégalités ?. Les dossiers des sciences de l'éducation, [S.L]. $\mathrm{n}^{\circ} 36$, p. 109-129, 2016. Disponível em: https://journals.openedition.org/dse/1397. Acesso em 08.05.2019.

BONNÉRY, S. Supports pédagogiques et inégalités scolaires, Paris: La Dispute, 2015.

BRUNER, J. Pourquoi nous racontons-nous des histoires. Paris, Retz, 2005.

DELARUE-BRETON, C.; BAUTIER, É. Nouvelles littératies scolaies et inégalité des élèves: une production de signification différenciée. Le Français aujourd'hui, [S.L]. 190, p. 51-60, $2015 \mathrm{a}$.

DELARUE-BRETON, C.; BAUTIER, É. Restitution de récit et nouvelle littératie scolaire: Étude comparée de productions orales d'élèves issus d'établissements scolaires de milieux contrastés. SHS web of Conferences, 16, 02003, 2015b. Disponível em: $<$ http://dx.doi.org/10.1051/shsconf/20151602003> Acesso em 08.05.2019.

FORQUIN, J.-C. (2008), Sociologie du curriculum. Rennes: PUR.

FRAENKEL, B.; MBODJ, A. (Dir.). New literacy studies, un courant majeur pour l'écrit. Langage \& société, [S.L]. 133, 2010.

GOODY, J. Pouvoirs et savoirs de l'écrit. Traduction française Claire Maniez. Paris: La Dispute, 2007.

LAHIRE, B. Culture écrite et inégalités scolaires: sociologie de l'échec scolaire à l'école primaire. Lyon: Presses Universitaires de Lyonm 1993.

MAMEDE, M. (2011) La construction du cadre de la scolarisation comme contexte de littératie par les enseignants brésiliens. Recherches en Education. Hors Série no. 3 - Octobre. 105-116, 2011. 
OCDE (2016). Note par pays. Programme international poiur le suivi des acquis des élèves PISA. Resutlats du PISA 2015. France. Disponível online: <http://www.oecd.org/pisa/PISA2015-France-FRA.pdf> Acesso em 08.05.2019.

OLSON, D. R. L'univers de l'écrit. Comment la culture écrite donne forme à la pensée. Paris: Retz, 1994.

OLSON, D. R.; LEJOSNE, J.-C. Littératie, scolarisation et cognition. Quelques implications de l'anthropologie de Jack Goody. Pratiques, [S.L]. 131-132, p. 83-94, 2006.

REUTER, Y. À propos des usages de Goody en didactique. Éléments d'analyse et de discussion. Pratiques, [S.L]. 131-132, 2006. Disponível online: $<$ https://doi.org/10.3406/prati.2006.2124> Acesso em 08.05.2019.

ROCHEX, J.-Y., CRINON, J. La construction des inégalités scolaires. Au cour des pratiques et des dispositifs d'enseignement. Rennes: Presses Universitaires de Rennes, 2011.

STREET, B. Cross-cultural approaches to literacy. Cambridge, Cambridge University Press, 1993.

VAQUERO, S. Réussir ses TPE. Une sociologie de la domination scolaire et culturelle au sein des dispositifs pédagogiques du lycée. Tese sob a orientação de Mathias Millet. Université de Poitiers, 2019.

Elisabeth Bautier bautier@wanadoo.fr

Maíra de Araujo Mamede maira.mamede@,u-pec.fr

Recebido em: 14 de Julho de 2019 Aceito em: 17 de Agosto de 2019 Publicado em: Setembro de 2019 